\title{
The Integration of Supply Chain Coordination in Higher Education Supply Chain Framework
}

\author{
Mohammed Ahmed Waham ${ }^{\mathrm{a}}$, Fitra Lestari ${ }^{\mathrm{b}}$ \\ ${ }^{\text {a }}$ University of Misan,Amarah, Iraq \\ ${ }^{\mathrm{b}}$ Sultan Syarif Kasim State Islamic University, Riau, Indonesia \\ Correspondence author: mohammedwaham1@gmail.com
}

\begin{abstract}
The purpose of this conceptual paper is to develop the education supply chain framework by integrating the supply chain coordination dimensions that are information sharing, commitment, joint decision making and responsiveness. A qualitative framework analysis methodology proposed by Srivastava and Thomson (2009) will be performed by interviewing seven groups of supply chain actors (schools/polytechnics, university, employers, government, professional bodies, current students and alumni) until data saturation is reached to understand the participants' experiences about supply chain coordination. The interview data will be analysed by using thematic analysis and emerging themes will help to explain the education supply chain framework from supply chain coordination perspectives. In education supply chain context, this is the first attempt to embed the selected supply chain coordination dimensions in the existing framework. Education supply chain actors could benefit from this framework by performing better coordination to reduce the education-job mismatch.
\end{abstract}

\section{Keywords:}

Education supply chain, supply chain coordination, supply chain management, education-job mismatch, supply chain coordination framework

\section{INTRODUCTION}

Education system has been developed in countries around the world to produce human capital for the labour market. It provides learning opportunities for children and adults to develop cognitive abilities, practical skills and expected behaviour so they can contribute to the society. For that reason, formal learning starts from early childhood and continues to elementary and secondary school level until higher education.

However, what considered being important cognitive and skill competencies in the education system has changed over time to align with the need of the industries. Lending support to that statement, previous studies reported overeducated and over skilled of graduates which created a mismatch between education and skill with employment requirement. A review study which examined about horizontal mismatch, a condition where employees' field degree is poorly matched with the job requirements, found that horizontal mismatch incident rates ranged between 21 to 46 percent across different studies conducted worldwide (Somers, Cabus, Groot, \& van den Brink, 2019).

In European countries particularly, around 15 to 35 percent of the employees experienced vertical mismatch where they were over- or undereducated for their current jobs while 20 to 50 percent were employed for the jobs that do not fit the usual field of qualifications (Morgado, Sequeira, Santos, Ferreira-Lopes, \& Reis, 2016). Similar evidence were found in Poland where many of the educated employees were hired for positions 
requiring less qualifications (Bebel, Piotrowska, \& Kosny, 2018). In addition, a study conducted in India confirmed that 1 in 4 employees perceived that they were overqualified for their jobs and 1 in 8 employees thought that they were underqualified (Patil \& Patil, 2019). Further evidence showed that the right match was more likely to occur among people without tertiary education (Karymshakov, 2019)

The effect of education-job mismatch in terms of the pay did not further help to lessen the magnitude of this issue. It was found that overeducated employees whose working in different field of their studies did not receive additional payoff to years of surplus education (Pecoraro, 2016). A study in Thailand revealed that employees facing education-job mismatches had lower monthly incomes compared to other who did not (Pholphirul, 2017). Male and overeducated employees earned lower wages than the well matched (Karymshakov, 2019). Moreover, in a short term, graduates with horizontal, vertical or mere mismatch experienced 21 percent higher probability of being in a part-time work (Li, Harris, \& Sloane, 2018). In a long run, education-job mismatch will increase brain drain where certain countries attract highly talented people through emigration and leave other countries without any talent or skills for their growth (Pride \& Tatenda, 2017; Ullah, 2019).

The answer to this problem lies within the linkage between the education system and the institutional (Somers, et al., 2019). In the case of migrants, migrant network had been found to be an effective measure to combat negative vertical mismatch although it did not make any significant difference for horizontal mismatch (Chort, 2017). Failure in meeting market demands, which rooted from unanticipated challenges arising from intra-regional labour flows and disruption technology among others, demanded an education system overhaul (Ullah, 2019). In response to that suggestion, this research attempts to develop an effective education supply chain by integrating the supply chain coordination concept.

\section{Education Supply Chain}

The development of an academic program depends on a number of factors. According to Gillespie and Bampasidou (2018), these factors could be categorized into two namely internal and external factors. Internal factors which influence academic program development include (1) desired attributes for college students, (2) observed student strengths and weaknesses, (3) evaluation of peer programs, and (4) student input. Meanwhile, (1) employer feedback, (2) regional employment opportunities, and (3) alumni perceptions were considered as the external factors determining the development of an academic program. Bolgova, Grodskaya and Kurnikova (2020) proposed further extension to the factors influencing the development of academic program by introducing the role of the government in setting strategic direction which led to changes in labour market requirement.

In line with the previous studies mentioned above, the most important shaper of an academic program is the state's board of higher education or the government (Al Wahshi, 2016; Dee \& Heineman, 2016). The state's board approve or disapprove a new degree program depending on whether the program achieves the quality standards, the offering institutions own sufficient educational resources to deliver the program and whether the program has promising labour market projections for the graduates. In professional fields such as accountancy, professional bodies and accreditation association further affect the curriculum standards (Dee \& Heineman, 2016). Students undergoing an academic program may also propose other areas in their studies that they wish to acquire more training and preparation (Dee \& Heineman, 2016). Whereas, by joining the advisory board, employers 
become the source of academic program development who supply critical information regarding emerging trends in the field (Dee \& Heineman, 2016). Besides, the feedbacks from the alumni (Dee \& Heineman, 2016) supported by job ads data (Lopatovska \& Baribeau, 2017 ) could be used as an evaluation to improvise an academic program. Finally, observation of other academic institutions would identify underserve academic programs which could be an attractive opportunities for a new academic program development (Dee \& Heineman, 2016).

Based on these factors, the development of academic program could be applied to the supply chain concept. Supply chain management could be defined as the flow of services and information to transform raw materials into finished products. Srivastava and Pandey (2013) proposed a higher education supply chain which comprised of three levels; family, school/polytechnic, universities and employers as depicted in Figure 1. Family and school/polytechnic refer to the supplier, while university and employers represent the manufacturer and customers respectively. This framework bolstered the work of Habib and Jungthirapanich (2008) and Pathik, Habib and Chowdhury (2012) about simplified form of supply chain for the university. According to Figure 1, higher education supply chain links actors of the supply chain through the accumulation of knowledge and skills of an individual from the family, schools/polytechnics until university. In this framework, individuals were considered as raw materials that were transformed into finished good called graduates to fulfil the labour market. Despite that, this framework did not explicitly exhibit the coordination between supply chain actors which could contribute to reduce the education-job mismatch.

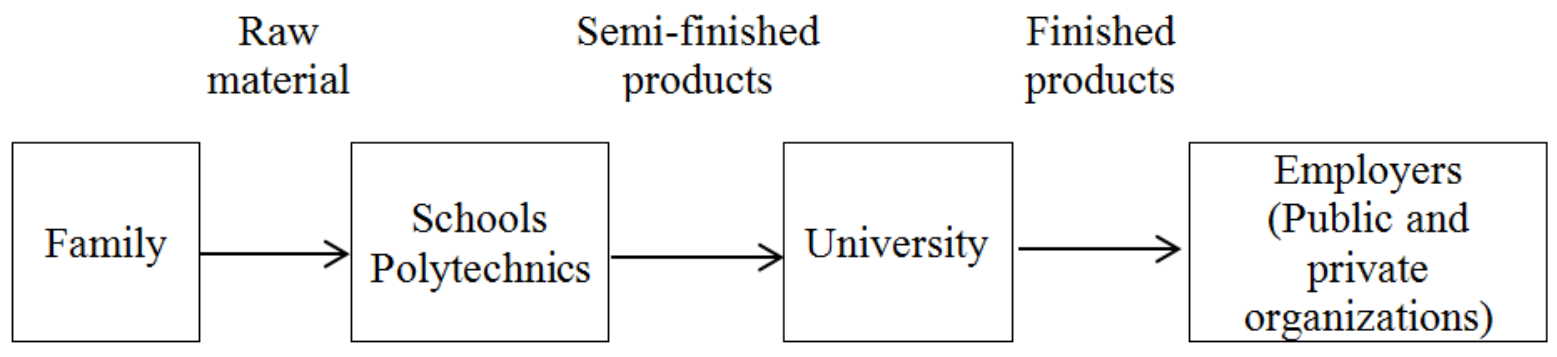

Figure 1: Higher education supply chain

Source: Pathik, Habib and Chowdhury (2012)

\section{Supply Chain Coordination}

Supply chain coordination is harmonized actions between organizations in a supply chain which aims to reduce waste and increase value creation (Balcázar-Camacho, López-Bello, \& Adarme-Jaimes, 2016). The importance of effective coordination is to reduce the information and "plug and play" misalignment (Piplani, 2005). Information misalignment happens when information necessary to support decision-making processes is not readily available, not usable or incorrect (Piplani, 2005). For example, some supply chain actors limited riskrelated information sharing with the other supply chain actors and resulted in the lack of preparation against risks (Hudin, Hamid, \& Chin, 2015). On the other hands, "plug and play" misalignment occurred because of the dynamic and rapid changes of customers' preferences and technology (Hudin, Hamid, Chin, \& Habidin, 2017; Piplani, 2005) which could be solved 
through information manufacturing sharing (Jaya, Habidin, Zubir, Conding, \& Hashim, 2012). This research argues that poor academic problem development is rooted from the lack of coordination among education supply chain actors especially when critical information such as the number of graduates needed, when they are needed and changes in the competencies needed are not discussed or shared, resulting in unnecessary programs.

Past studies explained several dimensions to measure supply chain coordination. Among the dimensions are information sharing (Lehoux, D'Amours, \& Langevin, 2014; Lotfi, Mukhtar, Sahran, \& Zadeh, 2013; Rajesh K Singh, 2011), commitment (Dubey, Altay, \& Blome, 2017; Rajesh K Singh, 2011), decision making (Lemma, Singh, \& Kaur, 2015; Rajesh K Singh, 2011), and responsiveness (Rajesh K Singh, 2011; Rajesh Kumar Singh, Kumar, \& Chand, 2019). In this study, these dimensions are embedded into the education supply chain framework to explore value-creation opportunities to reduce the adverse effects of education-job mismatch. The next section describes the conceptual framework of this study.

\section{Conceptual Framework}

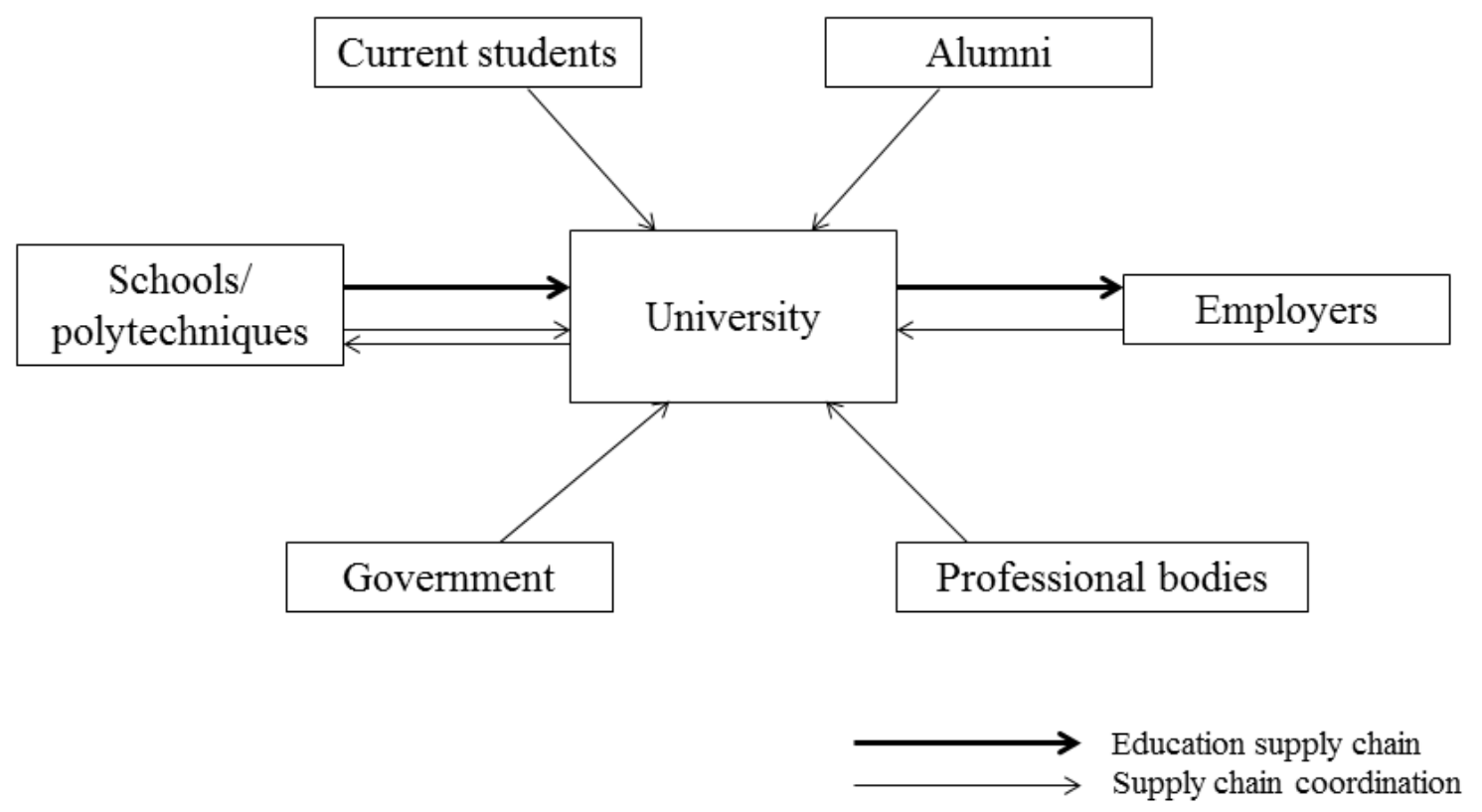

\section{Figure 2: Education supply chain framework through supply chain coordination}

Figure 2 illustrates the development of education supply chain through supply chain coordination. It shows the traditional link between education supply chain actors (schools/polytechnics, university and employers) and how supply chain coordination could be embedded within the relationships across all actors in terms of information sharing, commitment, joint decision making and responsiveness to better understand the labour market needs. This framework is parallel with the coordination theory which outlines the importance of exchanging information among actors who have to make interdependent decisions which eventually contribute to the same ultimate goal (Malone \& Crowston, 1990, 1994). The coordination theory contains four processes underlying coordination; (1) 
coordination, (2) group decision-making, (3) communication, and (4) perception of common object.

A coordination, which is setting a common goal and synchronizing activities between actors, can be achieved by an effective group decision making. Group decision making involves identifying alternatives, weighing pros and cons of each alternative and making choices together through consensus or voting so that all actors are considered in making an interdependent decision. To reach an effective group decision making, a good communication that comprised of establishing common languages and messages understood by all actors is necessary. This communication depends on the ability of actors to perceive common objects especially information, in the case of education supply chain.

The dependency of universities towards other actors in the supply chain for critical information in academic program development has yet been studied. Education-job mismatch has been traditionally being investigated from economics point of view but exploration from business angel is still scant. To authors' knowledge, this is the first study to embed the supply chain coordination into education supply chain, therefore a qualitative approach will be employed to explore how actors in the education system and the labour market coordinate to ensure that only relevant and appropriate education and skills are created to minimize the education and labour mismatch. The detail of the methodology will be explained in the subsequent section.

\section{METHODS}

The present study uses qualitative methodology to achieve the research objective. Data will be collected through interviews with academic program developers in schools and universities, employers, the department of human resource planning (government), professional bodies, final year university students, and university alumni. These research samples will be selected through purposive sampling technique based on predetermined criteria for each group of samples. Unlike a quantitative study, a qualitative study involves smaller sample, thus selecting knowledgeable, experienced, committed and most relevant unit of analysis is crucial. For that reason, the scope of the study will be narrowed down to participants involved in most poorly matched education-job program. To identify such program, information from exit survey conducted by universities on graduates upon convocation will be utilized. The interview protocol will contain five main sections as shown in Table 1 below. The interview protocol will be validated by three experts from the academic field and two experts from the industry. The data collection will be ended when saturation is reached. The data will be analysed based on framework analysis.

The research will employ framework analysis proposed by Srivastava and Thomson (2009) which consists of five steps; familiarization; identifying a thematic framework; indexing; charting; and mapping and interpretation. At the first step, familiarization, the researchers will immerse themselves in the data to get awareness of the major ideas and recurrent themes. Meanwhile, at the second step, researchers will identify a thematic framework based on priori issues and emerging themes from the data. Next, the researchers will identify and index interview excerpts correspond to a particular theme being identified in the third step. The fourth step, charting, requires the researchers to arrange the index of interview excerpts gathered in step 3 in a chart of themes. Finally, the researchers will map and interpret the themes arranged in the chart as a reflective of the participants' experiences, 
beliefs and perceptions. It will explain the participants' experiences about education supply chain coordination in a meaningful way.

Table 1: Sections in the interview protocol

\begin{tabular}{|c|c|c|}
\hline Section & $\begin{array}{c}\text { Supply Chain } \\
\text { Coordination Dimensions }\end{array}$ & Description \\
\hline 1 & Introduction & $\begin{array}{l}\text { General description of the participants' } \\
\text { role/responsibilities }\end{array}$ \\
\hline 2 & Information sharing & $\begin{array}{l}\text { Information sharing support technology, information } \\
\text { content, information quality (Zhou \& Benton Jr, } \\
\text { 2007). }\end{array}$ \\
\hline 3 & Commitment & $\begin{array}{l}\text { The willingness of a party to maintain a relationship } \\
\text { through the investment of financial, physical, or } \\
\text { relationship-based resources (Huo, Zhang, \& Zhao, } \\
\text { 2015). }\end{array}$ \\
\hline 4 & Joint decision making & $\begin{array}{l}\text { Two or more actors come to an agreement to make a } \\
\text { common decisions (Simatupang, Victoria Sandroto, } \\
\text { \& Hari Lubis, 2004) in order to avoid conflict } \\
\text { resulting from independent decision making } \\
\text { (Handayati, Simatupang, \& Perdana, 2015). }\end{array}$ \\
\hline 5 & Responsiveness & $\begin{array}{l}\text { Speed of reaction to market requirement (Rajesh } \\
\text { Kumar Singh, et al., 2019). }\end{array}$ \\
\hline
\end{tabular}

\section{CONCLUSION}

This conceptual paper aims to propose an education supply chain framework by integrating supply chain coordination concept. Based on education supply chain framework developed by Pathik, Habib and Chowdhury (2012) and supply chain coordination dimensions (information sharing, commitment, joint decision making and responsiveness), a qualitative methodology will be conducted to explore the extent of education supply chain actors' experiences in coordinating their activities to reach a common goal. This proposed education supply chain framework is a first attempt in integrating supply chain coordination context to help resolve education-job mismatch. The implication of this study is the extension of education supply chain framework in the supply chain management discipline. In practical, this framework offers an innovative solution towards coordination problems between universities and employers particularly in the development of new academic program which currently causing education-job mismatch. For future research, the role of supply chain leadership should be included in this framework to ensure the high performance of education supply chain. Moreover, a quantitative study should be conducted to measure the effectiveness of the proposed education supply chain framework.

\section{REFERENCES}

Al Wahshi, Adnan S. (2016). Human resource planning practices in the Omani Public Sector: An exploratory study in the Ministry of Education in the Sultanate of Oman.

Balcázar-Camacho, Delio Alexander, López-Bello, Cesar Amílcar, \& Adarme-Jaimes, Wilson. (2016). Strategic guidelines for supply chain coordination in healthcare and a mathematical model as a proposed mechanism for the measurement of coordination effects. Dyna, 83(197), 203-211. 
Bebel, Anna, Piotrowska, Maria, \& Kosny, Marek. (2018). Polish Labor Market: Issues of Over and Underemployement among Highly Educated Employees. Economic and Social Development: Book of Proceedings, 37-46.

Bolgova, EV, Grodskaya, GN, \& Kurnikova, MV. (2020). The Model for Meeting Digital Economy Needs for Higher Education Programs Digital Transformation of the Economy: Challenges, Trends and New Opportunities (pp. 542-556): Springer.

Chort, Isabelle. (2017). Migrant network and immigrants' occupational mismatch. The Journal of Development Studies, 53(11), 1806-1821.

Dee, Jay R, \& Heineman, William A. (2016). Understanding the organizational context of academic program development. New Directions for Institutional Research, 2015(168), 9-35.

Dubey, Rameshwar, Altay, Nezih, \& Blome, Constantin. (2017). Swift trust and commitment: The missing links for humanitarian supply chain coordination? Annals of Operations Research, 1-19.

Gillespie, Jeffrey M, \& Bampasidou, Maria. (2018). Designing Agricultural Economics And Agribusiness Undergraduate Programs. Journal of Agricultural and Applied Economics, 50(3), 319-348.

Habib, Md Mamun, \& Jungthirapanich, Chamnong. (2008). An integrated framework for research and education supply chain for the universities. Paper presented at the 2008 4th IEEE International Conference on Management of Innovation and Technology.

Handayati, Yuanita, Simatupang, Togar M, \& Perdana, Tomy. (2015). Agri-food supply chain coordination: the state-of-the-art and recent developments. Logistics Research, $8(1), 5$.

Hudin, Norlaile Salleh, Hamid, Abu Bakar Abdul, Chin, Thoo Ai, \& Habidin, Nurul Fadly. (2017). Exploring Supply Chain Risks among Malaysian Automotive SMEs. International E-Journal of Advances in Social Sciences, 3(8), 666-674.

Hudin, Norlaile Salleh, Hamid, Abu Bakar, \& Chin, Thoo Ai. (2015). Case Studies of Risk Communication in Automotive Part Manufacturers. Advanced Science Letters, 21(5), 1575-1578.

Huo, Baofeng, Zhang, Cheng, \& Zhao, Xiande. (2015). The effect of IT and relationship commitment on supply chain coordination: a contingency and configuration approach. Information \& Management, 52(6), 728-740.

Jaya, NASL, Habidin, Nurul Fadly, Zubir, AFM, Conding, J, \& Hashim, S. (2012). Exploring information manufacturing sharing and supply chain performance: based on Malaysian automotive industry. IOSR Journal of Engineering, 2(7), 41-48.

Karymshakov, Kamalbek. (2019). The school-to-work transition, overeducation and wages of youth in Kyrgyzstan. ahead-of-print(ahead-of-print). doi: 10.1108/IJM-02-2018-0054

Lehoux, Nadia, D’Amours, Sophie, \& Langevin, André. (2014). Inter-firm collaborations and supply chain coordination: review of key elements and case study. Production Planning \& Control, 25(10), 858-872.

Lemma, Habtamu Regassa, Singh, Rajwinder, \& Kaur, Navjot. (2015). Determinants of supply chain coordination of milk and dairy industries in Ethiopia: a case of Addis Ababa and its surroundings. SpringerPlus, 4(1), 498. doi: 10.1186/s40064-015-1287$\mathrm{X}$

Li, Ian W, Harris, Mark, \& Sloane, Peter J. (2018). Vertical, horizontal and residual skills mismatch in the Australian graduate labour market. Economic Record, 94(306), 301315.

Lopatovska, Irene, \& Baribeau, Hilary. (2017). What information professionals need to know: Job ads analysis. Proceedings of the Association for Information Science and Technology, 54(1), 747-749. 
Lotfi, Zahra, Mukhtar, Muriati, Sahran, Shahnorbanun, \& Zadeh, Ali Taei. (2013). Information sharing in supply chain management. Procedia Technology, 11, 298-304.

Malone, Thomas W, \& Crowston, Kevin. (1990). What is coordination theory and how can it help design cooperative work systems? Paper presented at the Proceedings of the 1990 ACM conference on Computer-supported cooperative work.

Malone, Thomas W, \& Crowston, Kevin. (1994). The interdisciplinary study of coordination. ACM Computing Surveys (CSUR), 26(1), 87-119.

Morgado, António, Sequeira, Tiago Neves, Santos, Marcelo, Ferreira-Lopes, Alexandra, \& Reis, Ana Balcão. (2016). Measuring labour mismatch in Europe. Social Indicators Research, 129(1), 161-179.

Pathik, Bishwajit Banik, Habib, Md M, \& Chowdhury, MT. (2012). Analysis of Educational Supply Chain Management Model: A Case Study Approach. Paper presented at the Proceedings of the 2012 International Conference on Industrial Engineering and Operations Management, Istanbul, Turkey.

Patil, Vinay R, \& Patil, Shailendra R. (2019). A Study of Job-Education Match/Mismatch among working professionals-An Indian Perspective. Journal for Research, 4(11), 17.

Pecoraro, Marco. (2016). The incidence and wage effects of overeducation using the vertical and horizontal mismatch in skills: Evidence from Switzerland. International Journal of Manpower, 37(3), 536-555.

Pholphirul, Piriya. (2017). Educational mismatches and labor market outcomes: Evidence from both vertical and horizontal mismatches in Thailand. Education+ Training, 59(5), 534-546.

Piplani, Rajesh. (2005). A coordination framework for supply chain inventory alignment. Journal of Manufacturing Technology Management, 16(6), 598-614. doi: 10.1108/17410380510609465

Pride, Mkandatsama, \& Tatenda, Nyanhete. (2017). Human Resource Planning in an Unstable Economy: Challenges Faced. A Case of State Universities in Zimbabwe. International Journal of Asian Social Science, 7(3), 206-217.

Simatupang, Togar M, Victoria Sandroto, Indah, \& Hari Lubis, SB. (2004). Supply chain coordination in a fashion firm. Supply Chain Management: An International Journal, 9(3), 256-268.

Singh, Rajesh K. (2011). Developing the framework for coordination in supply chain of SMEs. Business Process Management Journal, 17(4), 619-638.

Singh, Rajesh Kumar, Kumar, Pravin, \& Chand, Mahesh. (2019). Evaluation of supply chain coordination index in context to Industry 4.0 environment. Benchmarking: An International Journal.

Somers, Melline A, Cabus, Sofie J, Groot, Wim, \& van den Brink, Henriëtte Maassen. (2019). Horizontal mismatch between employment and field of education: Evidence from a systematic literature review. Journal of Economic Surveys, 33(2), 567-603.

Srivastava, Aashish, \& Thomson, S Bruce. (2009). Framework analysis: a qualitative methodology for applied policy research. Journal of Administration and Governance, 4(2), 72-79.

Srivastava, HS, \& Pandey, Praveen. (2013). Curriculum development in the Technical Education Supply Chain of Papua New Guinea. Paper presented at the The 7th HUON Seminar 2013, Papua New Guinea.

Ullah, A. K. M. Ahsan. (2019). Global skills deficiency: perspectives of skill mobility in Southeast Asian countries. Asian Education and Development Studies, 8(4), 416-432. doi: 10.1108/aeds-12-2018-0185 
International Business Education Journal Vol. 12 No. 1 (2019) 53-61

Zhou, Honggeng, \& Benton Jr, WC. (2007). Supply chain practice and information sharing. Journal of Operations management, 25(6), 1348-1365. 